\title{
Mantle source heterogeneity inferred from olivine-hosted melt inclusions
}

\author{
Mischa BöHNKE ${ }^{1}$, Felix Genske, ANDREas Stracke \\ Institut für Mineralogie, Westfälische Wilhelms-Universität, \\ Münster, Germany \\ 1mischa.boehnke@uni-muenster.de
}

The geochemical and isotopic composition of Earth's mantle is mostly investigated through bulk rock analyzes of MORB and OIB [1]. These are aggregate melts formed by mixing melts from different mantle source components. In contrast, olivine-hosted melt inclusions (MI) are small-volume fractional melts trapped during ascent and melt ponding in the shallow mantle and crust. They thus represent less complete mixtures than their host basalts. As such, MI have revealed a greater variety of compositions, and thus a larger extent of compositional variability of the mantle source than the erupted melts [e.g., 2].

Previous Ml studies have also resolved significant variation in radiogenic isotope ratios within single lava flows and have identified compositions not observed in the erupted melts $[3,4,5]$. These observations have important implications for the extent and scale of isotopic heterogeneity within Earth's mantle, and crust-mantle dynamics in general [3].

We have developed a time-efficient procedure for isolating $\mathrm{Ml}$ from their olivine host with a miniaturized core drill. This technique allows analyzing the chemical and $\mathrm{Sr}(\mathrm{Nd})$ isotopic compositions of individual MI by MC-ICPMS. First results on inclusions from primitive olivines in OIB from different islands, e.g., the Azores (Flores \& Corvo) and Tristan da Cunha, show that individual inclusions have distinct $\mathrm{Sr}$ isotopic signatures, which by far exceed the range observed in the erupted lavas in case of Tristan, and a more restricted, but still resolved, isotopic range relative to the host rocks at Flores and Corvo. The observed differences in the relative and absolute isotopic range between islands are due to variable source heterogeneity and efficiency of melt mixing during transport and evolution in the crust.

[1] Stracke, A., 2012, Chem. Geol., 330:274-299; [2]

Reinhard et al., 2018, Chem. Geol., 495: 36-49; [3] Stracke et al., 2019, Nat. Geosci., 12(10):851-855; [4] Sobolev et al., 2011, Nature, 476(7361):434-437; [5] Maclennan, J., 2008, Geochim. Cosmochim. Acta, 72(16):4159-4176. 